\title{
Green Alga Haematococcus Pluvialis a Potential Source of Pharmaceutical Valuable Astaxanthin
}

\section{Rather A H* and Singh S}

Algal Biotechnology Laboratory, Department of Post Graduate Studies and Research in Biological Science, Rani Durgavati University, India

*Corresponding author: Ashaq Hussain Rather, Algal Biotechnology Laboratory, Department of Post Graduate Studies and Research in Biological Science, Rani Durgavati University, Jabalapur, India, Email: ashaqabl2015@gmail.com

\section{Mini Review \\ Volume 3 Issue 2}

Received Date: October 16, 2018

Published Date: November 15, 2018

DOI: $10.23880 /$ oajmb-16000132

\section{Abstract}

Haematococcus pluvialis is one of the richest sources of natural astaxanthin which is considered as "super anti-oxidant." Astaxanthin has umpteen applications in the nutraceuticals, cosmetics, food, and aquaculture industries, can significantly decimate free radicals, oxidative stress and help human body maintain a healthy state. With extraordinary potency and increase in demand, astaxanthin is one of the high-value microalgae products of the future. This comprehensive review summarizes different sources of astaxanthin, occurrence, life cycle of $H$. pluvialis and applications of astaxanthin for human and animals.

Keywords: Haematoccoccus pluvialis; Astaxanthin; Nutraceuticals; Oxidative stress

\section{Introduction}

Astaxanthin is a xanthophyll carotenoid [1]. The main biological sources of astaxanthin are crustacea crustacean extracts, the green microalga Haematococcus pluvialis, the yeast Rhodotorula rubra, and the red yeast Phaffia rhodozyma. The aforementioned natural sources cannot compete with the synthetic products available [2] Crustacean meals have low levels of astaxanthin and high levels of moisture, ash and chitin. The algae Haemotococcus pluvialis has a relatively high concentration of astaxanthin, the yeast, has been reported to contain astaxanthin [3] but due to the presence of extremely thick cell wall, which hinders the extraction of astaxanthin from Rhodotorula rubra. Some bacterial species (Mycobacterium lacticola) produce astaxanthin only in hydrocarbon medium not on nutrient agar [4] have reported astaxanthin in floral parts of Tagetes erecta and Circubita maxima marica, but the seasonal and geographic variations [5] and the amount of astaxanthin compared to the total mass of the plant is quite small, therefore plants were not considered a suitable source for commercial cultivation [6]. Another source of astaxanthin was found in some yeast genera of Peniophora and Rhodotorula [7] but the pigment cannot be transformed by salmonids into astaxanthin [8] Astaxanthin production from algae has been studied such as Dunaliella salina [9], but the feeding trials using algae added to the salmonid feed showed a low uptake of pigments by the fish [10]. There are various other species of algae which has also been investigated as sources of astaxanthin [11-14]. Among them, the promising algal species investigated 
were Neochloris wimmeri [15], Chlamydomonas nivalis [16] and Dictyococcus cinnabarinus [17]. But the most promising algae as an astaxanthin source were considered green alga Haemotococcus pluvialis [18].

\section{Natural occurrence of $\boldsymbol{H}$. pluvialis}

H. pluvialis occurrence has been reported in different water bodies like artificial pools, natural and manmade ponds $[19,20]$ and has been isolated from different regions of Europe, Africa, North America, and Himachal Pradesh India [21, 22].

\section{Life Cycle H. Pluvialis}

The life cycle of $H$. pluvialis consists of four types of cells, microzooids, macrozooids, palmella (Green stage) and hematocysts (Red stage) shown in (Figures $1 \& 2$ ) $[23,24]$.

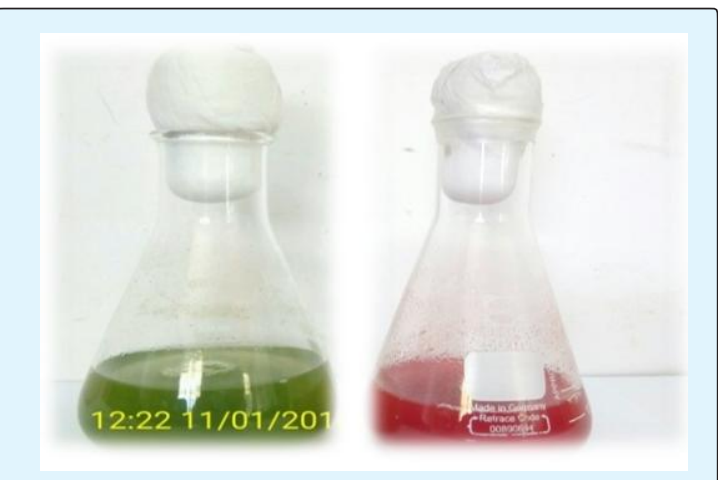

Figure 1: Green and red stage of $H$. pluvialis.

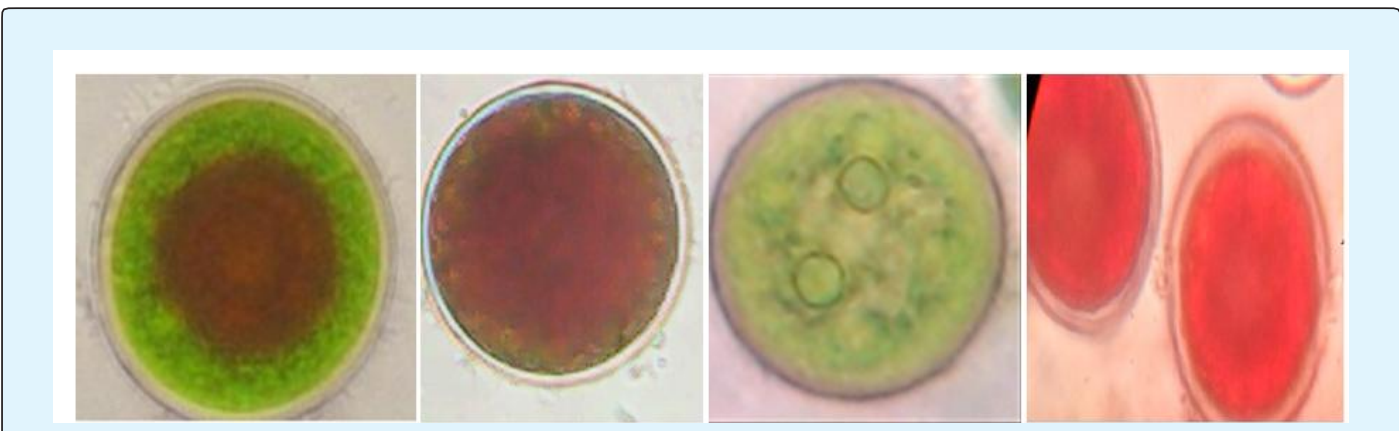

Figure 2: Light microscopic images of $H$. pluvialis cells.

Under favorable culture conditions, $H$. pluvialis cells remain in the green stage, under unfavourable environmental or culture conditions enter into a resting red stage [23]. The red stage of $H$. pluvialis is rich in astaxanthin shown in Figure 2.

\section{Applications of H. Pluvialis Astaxanthin}

Astaxanthin is a ketocarotenoid or oxygenated derivative of carotenoid, was first chemically identified by Kuhn and Sorenson (1879) as seen in Figure 3 [25].

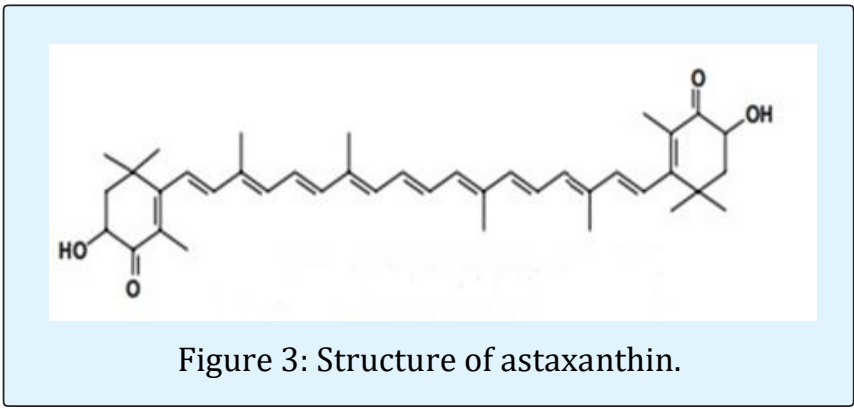

Under normal aerobic metabolism of organisms, produces oxidative molecules, which are known as free radicals or molecules with unpaired electron e.g. hydroxyls, peroxides, reactive oxygen species (singlets) which are innocuous and essential for sustaining of different life processes but excess production of such compounds are harmful to the various biomolecules such as proteins, lipids, carbohydrates and DNA [26] which results in aging, retinopathy, carcinogenesis, arteriosclerosis, and Alzheimer disease. However in order to subsidise these damages, the human body generates its own enzymatic antioxidants such as superoxide dismutase, catalase and peroxidase etc., but it was found that these compounds are not enough to provide suitable protection against oxidative stress, therefore it was reported that consuming proper quantities of antioxidants like vitamin E controls these damages [27]. An antioxidant is a molecule which has the ability to decimate free radicals from a cell, astaxanthin prevents cell membrane from the damage of free radicals as shown in Figure 4 [28]. 


\section{Open Access Journal of Microbiology \& Biotechnology}

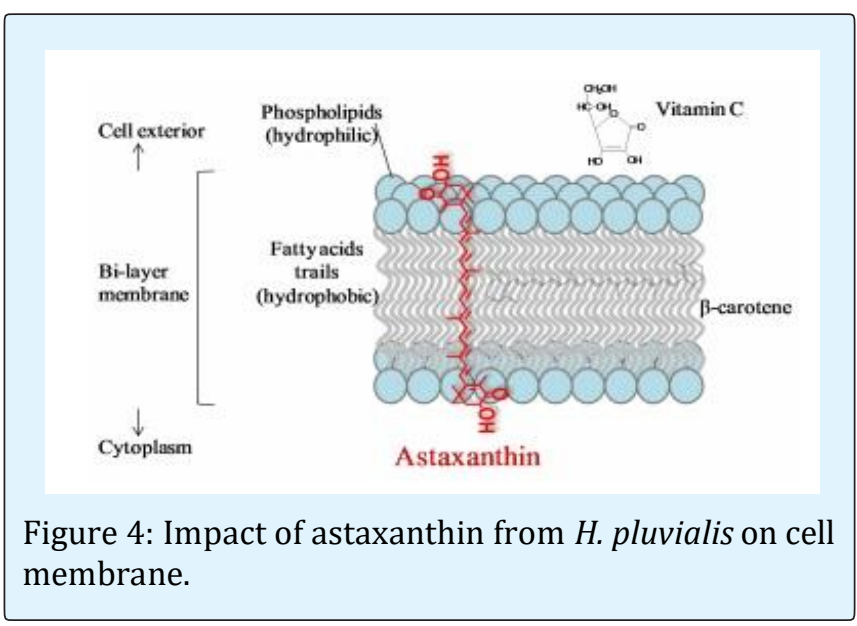

There are several other studies which showed high antioxidant activity of astaxanthin from $\mathrm{H}$. pluvialis in rats supplemented with astaxanthin formulated diet [29-31].

Astaxanthin from Haematococcus is safe and effective for flesh pigmentation of fish [32] as seen in Figure 5 [33].
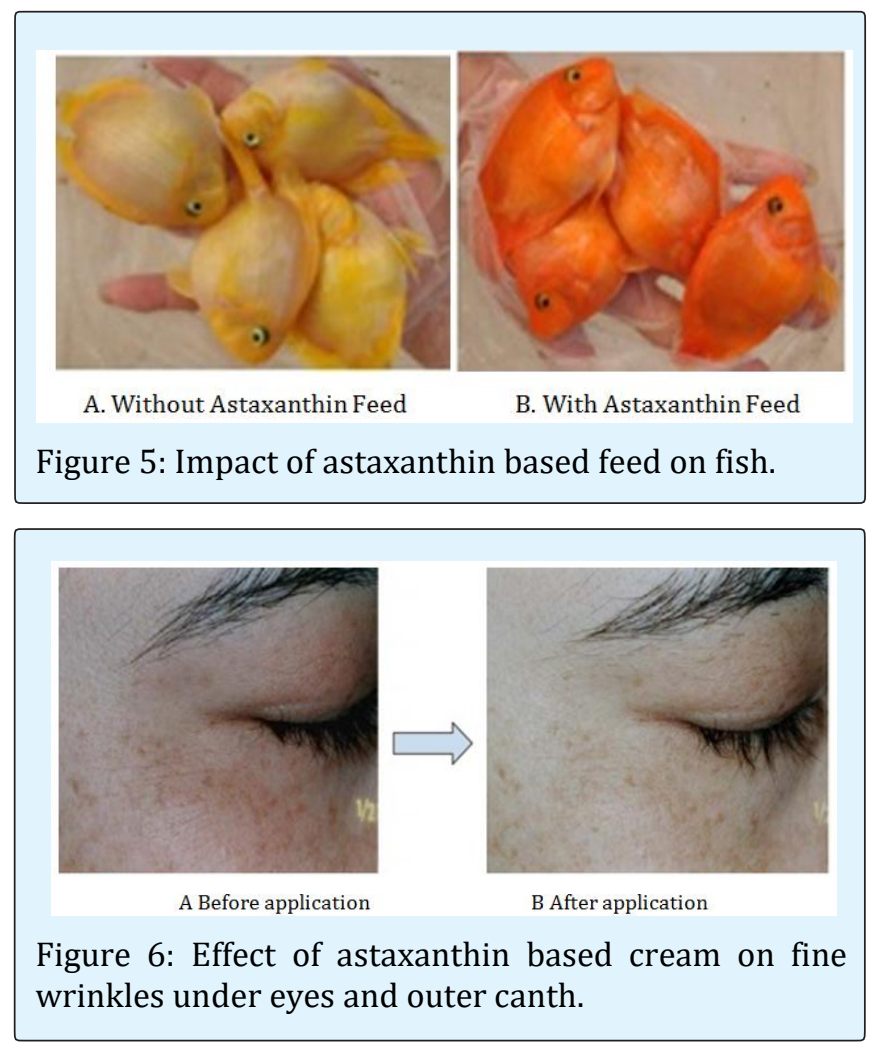

Consumption of $H$. pluvialis meal resulted in significant astaxanthin deposition in flesh and skin, which enhanced colour, antioxidant properties of fish, egg quality, better growth and survival of fry of salmonid, sea bream, and rainbow trout[34-38], ornamental fishes [39], and shrimp $[34,40]$. Astaxanthin from Haematococcus pluvialis was evaluated on human skin and was found safe for skin, confirmed by Patch Testing and Skin Repeated Application Test and it was observed that astaxanthin from $H$. pluvialis increased skin moisture retention, smoothness, elasticity of the skin improved the tendency of the fine wrinkles outer canthi and skin grain of cheeks as seen in Figure 6.

\section{Conclusion}

In recent years there is an increased interest for natural astaxanthin from green microalga $H$. pluvialis. Various scientific improvements have been achieved since the last decade in terms of production in order to obtain astaxanthin on large scale, however, there is a limited research work on astaxanthin based food Products on large scale. Future research should be focused on commercial production of astaxanthin based food products for human consumption.

\section{Acknowledgment}

We are thankful to the Head, Department of Post Graduate Studies and Research in Biological Science, Rani Durgavati University, Jabalpur-482001, (M.P.), India for providing necessary facilities. We are thankful to Mr. Aamir Hussain Rather and Ms Rekha Rao for providing language help.

\section{References}

1. Ciapara IH, Valenzuela LF, Goycoolea FM (2006) Astaxanthin: A review of its chemistry and applications. Critical Reviews in Food Science and Nutrition 46(2): 185-196.

2. Johnson EA, An GH (1991) Astaxanthin from Microbial Sources. Critical Reviews in Biotechnology 11(4): 297-326.

3. Ravinder P, Sangha K, Patel T, Martin AM (1995) Growth and pigmentation in Rhodotorula rubra and Phqffia rhodozyma. Journal of Basic Microbiology 35(l): 53-56.

4. Lee RG, Neamtu GG, Lee KC, Simpson KL (1978) Pigmentation of rainbow trout with extracts of floral parts from Tagetes erecta and Circubita maxima 


\section{Open Access Journal of Microbiology \& Biotechnology}

marica. Revue roumaine de biochimie 15(4): 287293.

5. Bell ER, White EB (1989) Flowers and plants as sources of food colourants. International Industrial Biotechnology 9(3): 609-614.

6. Kamata T, Tanaka Y, Yamada S, Simpson KL (1990) Study of carotenoid composition and fatty acids of astaxanthin diester in rainbow trout (Salmo gairdneiri) fed the Adonis extract. Nippon Suisan Gakkaishi 56(5): 789- 794.

7. Goodwin TW (1972) Carotenoids in fungi and nonphotosynthetic bacteria. Prog Ind Microbial 11: 2988.

8. Savolainen JET, Gyllenberg HG (1970) Feeding of rainbow trout with Rhodotorula sanneii preparations. 3. Amounts and qualities of carotenoids. Lebensmittel-Wissenschaft and Technologie 3: 18-20.

9. Borowitzka LJ, Borowitzka MA (1990) Commercial production of 5- carotene by Dunaliella salina in open ponds. Bulletin Marine Society 47: 244-235.

10. Kvalheim B, Knutson G (1985) Pigmentering av laks med astaxanthin fra mikroalger. Norsk Fiskeoppdrett 3: 4 .

11. Johansen JE, Svec WA, Jensen SL (1974) Carotenoids of the Dinophycae. Phytochemistry 13(10): 22612270 .

12. Choubert G (1979) Tentative utilisation of spirulina algae as a source of carotenoid pigments for rainbow trout. Aquaculture 18(2): 135-143.

13. Grung M, deSouza FM, Borowitzka MA, Jensen SL (1992) Algal carotenoids. 51. Secondary carotenoids. 2. Haematococcus pluvialis aplanospores as a source of (3S, 3'S)-astaxanthin esters. Journal of Applied Phycology 4(2): 165-171.

14. Wettern M, Weber A (1979) Some remarks on algal carotenoids and their conversion into animal carotenoids. In: Hoppe EA, et al. (eds.), Marine Algae in Pharmaceutical Science. Walter de Gruyer and Company Berlin, pp: 551.

15. Brown TE, Richardson FL, Vaughn ML (1967) Development of red pigmentation in Chlorococcus wimmeri (Chlorophyta: Chlorococcales). Phvcologia 6(4): 167-184.
16. Czygan FC (1968) Secondary carotenoids in green algae I. Chemistry, Occurrence and Factors Affecting the Formation of These Polyenes. Archives of Microbiology 61(1): 81-102.

17. Accadia FDD, Sassu OG, Rayes NL (1968) Blushing effect of some carbohydrates on the green alga Dictyococcus cinnabarius. Experimanta 24(11): 11771179.

18. Bubrick P (1991) Production of astaxanthin from Heamatococcus. Bioresource Technology 38(2-3): 237-239.

19. Czygan FC (1970) Blood-rain and blood-snow: nitrogen deficient cells of Haematococcus pluvialis and Chlamydomonas nivalis. Arch Microbiol 74(1): 69-76.

20. Burchardt L, Balcerkiewicz S, Kokocinski M, Samardakiewicz S, Adamski Z (2006) Occurrence of Haematococcus pluvialis Flotow emend. Wille in a small artificial pool on the university campus of the collegium biologicum in poznan (Poland). Biodiversity Research and Conservation 1: 163-166.

21. Pringsheim EG (1966) Nutritional requirements of Haematococcus pluvialis and related species. Journal of Phycology 2(1): 1-7.

22. Suseela MR, Toppo K (2006) Haematococcus pluvialis- A green alga, richest natural source of astaxanthin. Current science 90(12): 1602-1603.

23. Hagen C, Siegmund S, Braune W (2002) Ultrastructural and chemical changes in the cell wall of Haematococcus pluvialis (Volvocales, Chlorophyta) during aplanospore formation. European Journal of Phycology 37(2): 217-226.

24. Elliot A (1934) Morphology and life-history of Haematococcus pluvialis. Archives Protistenk 82(2): 250-272.

25. Visser H, Ooyen AJJ, Verdoes JC (2003) Metabolic engineering of the astaxanthin biosynthetic pathway of Xanthophyllomyces dendrorhous. FEMS Yeast Res 4(3): 221-231.

26. Mascio PD, Murphy ME, Sies H (1991) Antioxidant defense systems: the role of carotenoids, tocopherols and thiols. Am J Clin Nutr 53(1): 194-200. 


\section{Open Access Journal of Microbiology \& Biotechnology}

27. Burton GW, Ingold KU (1984) $\beta$-carotene: an unusual type of lipid antioxidant. Science 224(4649): 569573.

28. Britton G (1995) Structure and properties of carotenoids in relation to function. FASEB J 9(15): 1551-1558.

29. Kamath BS, Srikanta BM, Dharmesh SM, Sarada R, Ravishankar GA (2008) Ulcer preventive and antioxidative properties of astaxanthin from Haematococcus pluvialis. Eur J Pharmacol 590(1-3): 387-395.

30. Rao AR, Sindhuja HN, Dharmesh SM, Sankar KU, Sarada R, et al, (2013) Effective inhibition of skin cancer, tyrosinase, and antioxidative properties by astaxanthin and astaxanthin esters from the green alga Haematococcus pluvialis. J Agric Food chem 61(61): 3842-3851.

31. Augusti PR, Quatrin A, Somacal S, Conterato GM, Sobieskim R, et al. (2012) Astaxanthin prevents changes in the activities of thioredoxin reductase and paraoxonase in hypercholesterolemic rabbits. Clinical Journal of Biochemistry and Nutrition 51(1): 42-49.

32. Torrissen OJ, Naevdal G (1984) Pigmentation of salmonids, Genetical variation in carotenoid deposition in rainbow trout. Aquaculture 38(1): 5966.

33. Tieliang LI, Chuan HE, Zhihong MA, Xing W, Wentong Li, et al. (2016) Effects of Different Carotenoids on Pigmentation of Blood Parrot (Cichlasoma synspilum). Journal of Aquatic Research Development.
34. Arai S, Mori T, Miki W, Yamaguchi K, Konosu S, et al. (1987) Pigmentation of juvenile coho salmon with carotenoid oil extracted from Antarctic krill. Aquaculture 66(3-4): 255-264.

35. Sommer TR, Potts WT, Morrissy NM (1991) Utilization of microalgal astaxanthin by rainbow trout (Oncorhynchus mykiss). Aquaculture 94(1): 79-88.

36. Choubert G, Heinrich O (1993) Carotenoid pigments of the green alga Haematococcus pluvialis: assay on rainbow trout, Oncorhynchus mykiss, pigmentation in comparison with synthetic astaxanthin and canthaxanthin. Aquaculture 112(2-3): 217-226.

37. Sheikhzadeh N, Panchah IK, Asadpour R, Nasrabadi HT, Mahmoudi H (2012) Effects of Haematococcus pluvialis in maternal diet on reproductive performance and egg quality in rainbow trout (Oncorhynchus mykiss). Anim Reprod sci 130(1-2): 119-123.

38. Sheikhzadeh N, Nasrabadi HT, Oushani AK, Enferadi MHN (2012b) Effects of Haematococcus pluvialis supplementation on antioxidant system and metabolism in rain-bow trout (Oncorhynchus mykiss). Fish Physiol Biochem 38(2): 413-419.

39. Ako H, Tamaru CS (1999) Are feeds for food fish practical for aquarium fish. International Aqua Feeds 2: 30-36.

40. Parisenti J, Beirao LH, Maraschin M, Mourino JL, Nascimento V, et al. (2011) Pigmentation and carotenoid content of shrimp fed with Haematococcus pluvialis and soy lecithin. Aquacult Nutrition 17(2): 530-535. 